\title{
Osteoartritli hastalarda retina kalınlığının değerlendirilmesi
}

\author{
Evaluation of retinal thickness in patients with osteoarthritis
}

\author{
Nusret Ök, Gökhan Pekel
}

Gönderilme tarihi:23.11.2018

Kabul tarihi:05.12.2018

\begin{abstract}
Özet
Amaç: Diz osteoartritli hastalarda merkezi maküla ve retina sinir lifi tabakası kalınlıklarının değerlendirilmesi amaçlandı.

Gereç ve yöntem: Bu kesitsel ve karşılaştırmalı çalışmaya, 26 diz osteoartritli hastanın 26 gözü ve yaşcinsiyet olarak eşleştirilmiş 26 sağlıklı kontrolün 26 gözü alındı. Bütün katılımcılara görme keskinliği ölçümü, biyomikroskopi değerlendirmesi, havalı tonometre ile göz içi basınç ölçümü ve retina incelemesini içeren standart göz muayenesi yapıldı. Merkezi maküla ve retina sinir lifi tabakası kalınlıklarını ölçmek için optik koherens tomografi cihazı kullanıldı.

Bulgular: Diz osteoartritli hastaların ve sağlıklı kontrollerin ortalama yaşları sırasıyla $60,8 \pm 8,2$ ve $58,0 \pm 9,8$ yıldı $(p=0,46)$. Her iki grupta da 8 erkek ve 18 kadın katıımcı vardı $(p=1,00)$. Ortalama merkezi maküla kalınlığı osteoartritli hastalarda $264,2 \pm 22,1 \mu \mathrm{m}$ iken sağlıklı kontrollerde $262,9 \pm 20,1 \mu \mathrm{m}$ idi $(p=0,88)$. Ortalama retina sinir

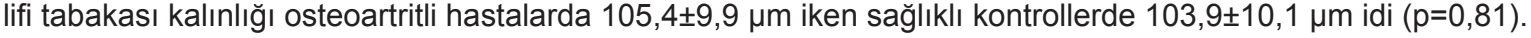
Sonuç: Merkezi maküla ve retina sinir lifi tabakası kalınlıkları osteoartritli hastalarda ve sağlıklı kontrollerde benzerdi.
\end{abstract}

Anahtar Kelimeler: Osteoartrit, merkezi maküla kalınlığı, retina sinir lifi tabakası.

Ök N, Peker G. Osteoartritli hastalarda retina kalınlığının değerlendirilmesi. Pam Tıp Derg 2019;12:123-126.

\begin{abstract}
Purpose: Our aim was to evaluate the thickness of central macula and retinal nerve fiber layer in patients with knee osteoarthritis.

Material and methods: Twenty-six eyes of 26 patients with knee osteoarthritis and 26 eyes of 26 age-gender matched healthy controls were included in this cross-sectional and comparative study. All participants underwent a standardized ophthalmological examination including visual acuity assessment, biomicroscopy evaluation, airpuff tonometry measurement and retinal examination. Optical coherence tomography was used to measure the thickness of central macula and retinal nerve fiber layer.

Results: The mean age of the patients with knee osteoarthritis and healthy controls were $60.8 \pm 8.2$ and $58.0 \pm 9.8$ years, respectively $(p=0.46)$. In both groups, there were 8 male and 18 female participants $(p=1.00)$. The mean central macular thickness was $264.2 \pm 22.1 \mu \mathrm{m}$ in the osteoarthritis group and $262.9 \pm 20.1 \mu \mathrm{m}$ in the healthy controls $(p=0.88)$. The mean retinal nerve fiber layer thickness was $105.4 \pm 9.9 \mu \mathrm{m}$ in the osteoarthritis group and $103.9 \pm 10.1 \mu \mathrm{m}$ in the healthy controls $(p=0.81)$.

Conclusions: The thicknesses of central macula and retinal nerve fiber layer were similar in patients with osteoarthritis and healthy controls.
\end{abstract}

Key Words: Osteoarthritis, central macular thickness, retinal nerve fiber layer.

Ök N, Peker G. Evaluation of retinal thickness in patients with osteoarthritis. Pam Med J 2019;12:123-126.

Nusret Ök, Dr. Öğr. Üyesi, Pamukkale Üniversitesi Tıp Fak. Ortopedi ve Travmatoloji AD. DENiZLi, e-posta:oknusret@gmail.com (orcid. org/0000-0003-3811-1884) (Sorumlu yazar)

Gökhan Pekel, Doç. Dr. Pamukkale Üniversitesi Tıp Fak. Göz Hastalıkları AD. DENiZLí, e-posta:gkhanpekel@yahoo.com (orcid.org/00000002-9509-8500) 


\section{Giriş}

Osteoartrit, dejeneratif bir eklem hastalığıdır ve sıklıkla 50 yaşın üzerindeki bireylerde gözlenir. En sık diz, el ve omurgayı etkilemekle birlikte, osteoartrit vücutta herhangi bir eklemi etkileyebilir [1, 2]. Diz osteoartriti patofizyolojisinde yaş, genetik yatkınlık, mekanik faktörler ve enflamasyon suçlanmaktadır [3]. Son yıllarda yapılan çalışmalarda diz osteoartriti gelişiminde ateroskleroz ve mikrovasküler patolojilerin rol oynadığı da gösterilmiştir [4, 5].

Sistemik hastalıklarda, mikrovasküler patolojileri gözlemek için uygun alanlardan birisi de retinadır. Retina tabakasını indirekt oftalmoskopi veya optik koherens tomografi cihazıyla detaylı olarak incelemek mümkündür. Diabetes mellitus ve hipertansiyon gibi çeşitli sistemik hastalıklarda, optik koherens tomografi cihazı kullanılarak retina katmanları ve damarlarındaki değişiklikler bilimsel literatüre sunulmuştur [6, 7]. Diz osteoartritli hastalarda da retina damarlarında incelme ile hastalık şiddetinin ilişkili olabileceği öne sürülmektedir [5].

Biz bu çalışmamızda, merkezi maküla kalınlığı ve retina sinir lifi tabakası kalınlıklarını diz osteoartritli hastalar ve sağlıklı kontrollerde karşılaştırmayı amaçladık. Patofizyolojisinde çeşitli mikrovasküler ve enflamatuar faktörlerin suçlandığı osteoartritte, bu tip etkenlerden sıklıkla etkilenen retina tabakasında değişiklikler olabileceğini varsaydık.

\section{Gereç ve yöntem}

Bu çalışma, Pamukkale Üniversitesi Ortopedi ve Travmatoloji ile Göz Hastalıkları kliniklerinde diz osteoartritli hastalar ve sağlıklı kontroller seçilerek gerçekleştirildi. Çalışma, Tıp Fakültesi Girişimsel Olmayan Etik Kurul onayı alındıktan sonra Helsinki deklerasyonu prensiplerine uygun olarak yapıldı.

Çalışmaya 26 diz osteoartritli hasta ve yaş-cinsiyet açısından hasta grubuyla benzer 26 sağııkı katıımcı alındı. Çalışmaya alınan hastalar, osteoartrit tanı ve tedavisini Ortopedi ve Travmatoloji kliniğinde alıp daha sonra Göz Hastalıkları kliniğine yönlendirildi. Bütün katılımcılara, otorefraktometre, görme keskinliği ölçümü, biyomikroskopi ile ön segment incelemesi, göz içi basınç ölçümü, retina incelemesi ve optik koherens tomografi (OKT) çekimlerini içeren standart oftalmoloji muayenesi yapıldı. Görme keskinliği ölçümü, Snellen eşeli ile ondalık sayı olarak kaydedildi. Göz içi basınç ölçümü havalı tonometre ile yapıldı. Hafif düzeyde kırma kusuru ve erken evre katarakt dışında herhangi bir oküler hastalığı olanlar çalışma dışı bırakıldı. Kırma kusuru \pm 3 'den büyük olanlar veya herhangi bir oküler cerrahi hikayesi olanlar çalışmaya alınmadı. Oküler yapıları etkileyebilecek diabetes mellitus ve sistemik hipertansiyon gibi hastalığı olanlar da çalışma dışı bırakıldı. Çalışmaya her hastanın sadece bir gözü dahil edildi.

Çalışmada kullanılan OKT cihazı (Spectralis, Heidelberg, Almanya) ile santral maküla kalınlığı ve peripapiller retina sinir lifi tabakası (RSLT) kalınlığı ölçüldü. Spectralis cihazı saniyede 40000 kesit alma hızında olup göz takip sistemi de mevcuttur. Santral maküla kalınlığı, foveada yaklaşık $1 \mathrm{~mm}$ 'lik alanda ölçüldü. RSLT ölçümleri ise optik diskin etrafında yaklaşık 3,5 $\mathrm{mm}$ çaplı çembersel çizgide, dört kadrandan (üst, alt, nazal ve temporal) yapıldı.

İstatistiksel analiz için SPSS 17.0 (Statistical Package for the Social Sciences, SPSS Inc., Chicago, ABD) programı kullanıldı. $P$ değerinin 0,05'den küçük olması istatistiksel olarak anlamlı kabul edildi. Gruplar arası karşılaştırmalarda Mann Whitney U-testi kullanıldı. Korelasyon analizlerinde Spearman testi uygulandı. Gruplara göre cinsiyet dağılımlarını analiz etmek için Ki-kare testi kullanıldı.

\section{Bulgular}

Bu çalışmada 26'sı diz osteoartritli hasta (çalışma grubu) ve 26'sı sağlıklı kontroller (kontrol grubu) olmak üzere toplam 52 katılımcı yer aldı. Çalışma ve kontrol gruplarının çeşitli demografik ve oküler özellikleri Tablo 1'de gösterilmiştir. Her iki grup da yaş, cinsiyet, görme keskinliği ve göz tansiyonu açısından benzer değerlere sahip bulundu $(p>0,05)$. Her iki grupta da 4 kişide hafif düzeyde katarakt saptandı $(p=1,00)$.

Osteoartritli hastaların ve sağlıklı kontrollerin RSLT ve santral maküla kalınlık ölçümleri Tablo 2 'de belirtilmiştir. Her iki grup da ortalama, alt, üst, nazal ve temporal kadran RSLT kalınlık ölçümleri açısından benzer değerlere sahip bulundu $(p>0,05)$. Ayrıca, santral maküla kalınlık değerleri açısından da her iki grup arasında istatistiksel anlamlı bir fark bulunmadı $(p>0,05)$. 
Osteoartritli grupta yaş ile ortalama RSLT kalınlığı $(p=0,81)$ ve santral maküla kalınlığı $(p=0,08)$ arasında istatistiksel anlamlı bir korelasyon saptanmadı. Ayrıca, osteoartritli grupta cinsiyetin ortalama RSLT kalınlığı ve santral maküla kalınlığına etkisine bakıldı; yine değişkenler arasında anlamlı bir ilişki saptanmadı $(p>0,05)$.

Tablo 1. Diz osteoartritli hastaların ve sağlıklı kontrollerin demografik ve oküler bazı özellikleri gösterilmektedir.

\begin{tabular}{llll}
\hline & Osteoartrit grubu & Kontrol grubu & $p$ değeri \\
\hline Ortalama yaş $(y ı l)$ & $60,8 \pm 8,2$ & $58,0 \pm 9,8$ & 0,46 \\
Cinsiyet $(E, K)$ & $8 \mathrm{E}, 18 \mathrm{~K}$ & $8 \mathrm{E}, 18 \mathrm{~K}$ & 1,00 \\
GK (Snellen, ondalık) & $0,97 \pm 0,07$ & $0,97 \pm 0,07$ & 1,00 \\
GiB $(\mathrm{mmHg})$ & $14,9 \pm 3,3$ & $15,8 \pm 1,9$ & 0,15 \\
\hline
\end{tabular}

E: erkek, K: kadın, GK: görme keskinliği, GiB: göz içi basıncı

Tablo 2. Diz osteoartritli hastaların ve sağlıklı kontrollerin retina sinir lifi tabakası (RSLT) ve santral maküla kalınlık (SMK) ölçümleri gösterilmektedir.

\begin{tabular}{llll}
\hline & Osteoartrit grubu & Kontrol grubu & $p$ değeri \\
\hline Ort. RSLT kal. $(\mu m)$ & $105,4 \pm 9,9$ & $103,9 \pm 10,1$ & 0,81 \\
Alt kad. RSLT kal. $(\mu m)$ & $134,4 \pm 15,7$ & $138,9 \pm 17,3$ & 0,31 \\
Üst kad. RSLT kal. $(\mu m)$ & $130,3 \pm 18,1$ & $122,7 \pm 15,0$ & 0,29 \\
Nazal kad. RSLT kal. $(\mu m)$ & $85,6 \pm 18,0$ & $80,7 \pm 12,9$ & 0,71 \\
Temp. kad. RSLT kal. $(\mu m)$ & $71,0 \pm 11,2$ & $72,5 \pm 10,4$ & 0,75 \\
SMK $(\mu m)$ & $264,2 \pm 22,1$ & $262,9 \pm 20,1$ & 0,88 \\
\hline
\end{tabular}

Ort.: ortalama, RSLT: retina sinir lifi tabakası, kal.: kalınlık, kad.: kadran, temp.: temporal, SMK: santral maküla kalınlığı

\section{Tartışma}

$\mathrm{Bu}$ çalışmanın en önemli sonucu, diz osteoartritli hastalar ve sağlıklı kontroller arasında, retina kalınlığı açısından önemli bir farkılık olmadığının tespit edilmesiydi. Retina, birçok vasküler ve enflamatuar patolojilerden sıklıkla etkilenebilen bir yapıda olmasına rağmen, osteoartritte fazlaca etkilenmemişti. Bu durum, diz osteoartritinin sistemik bir patoloji yapmaktan çok lokal bir patoloji oluşturduğuna işaret edebilir.

Santral maküla, görmede rol oynayan en önemli oküler yapılardan birisidir. Santral maküla kalınlığının yaş, cinsiyet ve kırma kusurundan etkilenebildiği gösterilmiştir [8]. $\mathrm{Bu}$ nedenle çalışmamızda hasta ve kontrol grupları yaş, cinsiyet ve kırma kusuru açısından benzer seçilmişti. Santral maküla kalınlığı hipertansiyon, diabetes mellitus ve sistemik sklerozis gibi birçok sistemik hastalıktan etkilenebilmektedir [9-11]. Bizim çalışmamızda osteoartrit hastalarında, maküla kalınlığında herhangi bir anormallik saptanmadı.
Retina sinir lifi tabakası kalınlığı birçok oküler ve sistemik hastalıkta incelmektedir [1215]. Glokom hastalığında bu tabakada incelme karakteristiktir [12, 13]. Çalışmamızda her iki grupta da göz içi basınç değerleri benzer saptandığından, bu durum gruplar arasında yanlıık (bias) oluşturmamıştı. Alzheimer hastalığı ve metabolik sendrom gibi dejeneratif hastalıklarda inceldiği gösterilen retina sinir lifi tabakasının osteoartritte incelmediği gözlendi $[14,15]$.

$\mathrm{Bu}$ çalışmanın çeşitli kısıtılıkları mevcuttu. İlk olarak hasta sayısı nispeten azdı. İkinci olarak, diz harici diğer eklemlerinde osteoartrit olan hastalar da çalışmaya alınabilirdi. Son olarak, retinadaki mikrovasküler değişiklikleri detaylı olarak gösterebilen OKT anjiografi tetkiki uygulanabilseydi, daha değerli bilgiler elde edilebilirdi.

Sonuç olarak, diz osteoartritinin santral maküla ve retina sinir lifi tabakası kalınlıklarına herhangi bir olumsuz etki göstermediği tespit edildi. İleriki çalışmalarda daha fazla sayıda hastanın farklı retina analiz yöntemleriyle 
incelenmesi, bu konu hakkında daha derinlemesine bilgi edinilmesine katkıda bulunabilir.

Çıkar İlişkisi: Yazarlar çıkar ilişkisi olmadığını beyan ederler.

\section{Kaynaklar}

1. Mora JC, Przkora R, Cruz-Almeida Y. Knee osteoarthritis: pathophysiology and current treatment modalities. J Pain Res 2018;11:2189-2196.

2. Nelson FRT. The value of phenotypes in knee osteoarthritis research. Open Orthop J 2018;12:105114.

3. Gardiner BS, Woodhouse FG, Besier TF, et al. Predicting knee osteoarthritis. Ann Biomed Eng 2016;44:222-233.

4. Hoeven TA, Kavousi M, Clockaerts S, et al. Association of atherosclerosis with presence and progression of osteoarthritis: the Rotterdam Study. Ann Rheum Dis 2013;72:646-651.

5. Hussain SM, Wang Y, Shaw JE, et al. Retinal arteriolar narrowing and incidence of knee replacement for osteoarthritis: a prospective cohort study. Osteoarthritis Cartilage 2015;23:589-593.

6. Ruia S, Saxena S, Gemmy Cheung CM, Gilhotra JS, Lai TY. Spectral domain optical coherence tomography features and classification systems for diabetic macular edema: A review. Asia Pac J Ophthalmol (Phila) 2016;5:360-367.

7. Chhablani PP, Ambiya V, Nair AG, Bondalapati S, Chhablani J. Retinal findings on OCT in systemic conditions. Semin Ophthalmol 2018;33:525-546.

8. Patel PJ, Foster PJ, Grossi CM, et al. Spectral-Domain optical coherence tomography imaging in 67321 adults: Associations with macular thickness in the UK biobank study. Ophthalmology 2016;123:829-840.

9. Alkuraya H, Kangave D, Abu El-Asrar AM. The correlation between optical coherence tomographic features and severity of retinopathy, macular thickness and visual acuity in diabetic macular edema. Int Ophthalmol 2005;26:93-99.

10. Ingegnoli F, Gualtierotti R, Pierro L, et al. Choroidal impairment and macular thinning in patients with systemic sclerosis: the acute study. Microvasc Res 2015;97:31-36.

11. Akay F, Gündoğan FC, Yolcu U, Toyran S, Tunç E, Uzun S. Retinal structural changes in systemic arterial hypertension: an OCT study. Eur J Ophthalmol 2016;26:436-441.

12. Townsend KA, Wollstein G, Schuman JS. Imaging of the retinal nerve fiber layer for glaucoma. $\mathrm{Br} \mathrm{J}$ Ophthalmol 2009;93:139-143.
13. Weinreb RN, Shakiba S, Sample PA, et al. Association between quantitative nerve fiber layer measurement and visual field loss in glaucoma. Am J Ophthalmol 1995;120:732-738.

14. Zarei R, Anvari P, Eslami YA, et al. Retinal nerve fibre layer thickness is reduced in metabolic syndrome. Diabet Med 2017;34:1061-1066.

15. GüneşA, Demirci S, Tök L, Tök Ö, Demirci S. Evaluation of retinal nerve fiber layer thickness in Alzheimer disease using spectral-domain optical coherence tomography. Turk J Med Sci 2015;45:1094-1097. 